\title{
A relação entre o estilo parental e o otimismo da criança
}

\author{
Lidia Natalia Dobrianskyj Weber ${ }^{1}$ \\ Olivia Justen Brandenburg \\ Ana Paula Viezzer
}

\begin{abstract}
Resumo
Esta pesquisa investigou se o otimismo da criança está relacionado ao estilo parental. Os dados provêm de 280 alunos (entre 9 e 12 anos), de duas escola públicas de Curitiba. Os pais foram classificados em um dos quatro estilos parentais (autoritativo, autoritário, indulgente e negligente), de acordo com o escore que seus filhos lhes deram nas duas escalas de responsividade e exigência parental. O otimismo das crianças foi acessado pelo Questionário de Estilo de Atribuição para Crianças. Testes estatísticos (Anova e Correlação) mostraram que pais autoritativos foram associados a maiores escores de otimismo e a menores escores de passividade, enquanto pais negligentes foram associados a menores escores de otimismo e a maiores escores de passividade. Esses resultados mostram que os pais possuem papel importante no processo de aprendizado do otimismo da criança, e sugere que crianças educadas por pais autoritativos estão melhor preparadas para enfrentar as adversidades de forma otimista.

Palavras-Chave: Otimismo; Estilo explicativo; Estilos parentais.
\end{abstract}

\section{The relationship between parenting style and child's optimism}

\begin{abstract}
This study investigated whether child optimism is related to parenting style. The data came from 280 students, aged 9 to 12 years, from two public schools in Curitiba. Parents were classified in one of the four parenting styles (authoritative, authoritarian, indulgent and neglectful), according to the scores children gave them on the two scales of parental responsiveness and demandingness. Children optimism was assessed by the Children's Attributional Style Questionnaire. Statistics tests (Anova and Correlation) showed that authoritative parents were associated to higher optimism scores and to lower hopelessness score, while negligent parents were associated to lower optimism scores and higher hopelessness score. These results show that parents has an important role on the learning processes of children's optimism, and suggest that children reared by authoritative parents are more prepared to face adversities in a optimist way.
\end{abstract}

Keywords: Optimism, Explanatory style, Parenting style.

\section{Introdução}

É preciso relembrar que a psicologia não é apenas o estudo da patologia, mas também o estudo dos aspectos positivos que fazem a vida valer a pena. A psicologia positiva vem justamente mudar o foco da psicologia, que está voltado apenas ao tratamento de problemas já existentes, para a construção de habilidades positivas ao ser humano (Seligman \& Csikszentmihalyi, 2000).

Dessa perspectiva é possível pensar nos trabalhos de prevenção da doença, não apenas de tratamento. As pesquisas de Seligman sobre o otimismo começaram com base em investigações sobre como prevenir a depressão em adultos e crianças. Nesse sentido, Seligman (1995) desenvolveu um programa de "imunologização" para crianças de idade escolar (The Penn Prevention Program). A expressão "imunologização" foi utilizada por Seligman numa analogia à vacinação, ou seja, ensinar o otimismo para a criança seria uma "vacina" contra a depressão.

Ser otimista não se reduz a pensamentos positivos. Seu fundamento se encontra na maneira como se pensa sobre causas (Seligman, 1995). A diferença entre o otimista e o pessimista está na forma de eles explicarem a causa de eventos ruins ou bons que lhes acontecem no cotidiano, ou seja, como é seu "estilo explicativo" (explanatory style).

Seligman (1995) apresenta três dimensões para explicar o porquê da ocorrência de um evento bom ou ruim. A primeira é a permanência, que se refere ao quanto os efeitos do evento se prolongam no tempo; a

${ }^{1}$ Endereço para correspondência:

Pç. Santos Andrade, 50, $1^{\circ}$ and. - Departamento de Psicologia - Curitiba-PR - 80060-000

E-mail: lidiaw@uol.com.br 
segunda é a difusão, que se refere ao quanto os efeitos do evento se propagam para outras situações; e a terceira é a personalização, que se refere ao quanto a causa é atribuída a fatores externos ou internos. Otimistas atribuem explicações permanentes, difundidas e internas para os eventos bons, e explicações temporárias, específicas e externas para eventos ruins. $\mathrm{O}$ contrário acontece para os pessimistas. Os eventos bons são vistos como temporários, específicos, e externos. $\mathrm{O}$ indivíduo acredita que o evento bom não foi determinado pelo seu próprio esforço para ocorrer. Os eventos ruins são vistos pelo pessimista como permanentes, difundidos e internos, culpando-se pelo acontecimento.

Culpar a si ou ao mundo (a personalização) é o que governa o sentimento da auto-estima, enquanto as outras duas dimensões (permanência e difusão) governam o que a criança vai fazer em resposta ao evento ruim (Seligman, 1995). Acreditar que os problemas vão durar para sempre e que vão determinar tudo na vida faz com que a criança pare de tentar. A desistência pode levar a falhas, gerando baixa autoestima. Assim, a permanência e difusão de eventos ruins deixam a criança sem esperanças (bopelessness); ela pára de tentar, desiste de novas oportunidades e fica passiva diante da derrota. Isso representa um passo rumo à depressão. A passividade está ligada à depressão como mostra a pesquisa de Kamen e Seligman (1987), em que pessoas depressivas se apresentaram passivas no que se referia à auto-ajuda, a autocuidados e aos desafios.

Portanto, pode-se compreender que a forma de o indivíduo explicar as causas de eventos bons e ruins, que é o estilo explicativo, está associada com a saúde futura dele (Kamen \& Seligman, 1987). Uma pesquisa retroativa, com pessoas com idade média de 72 anos, encontrou que o estilo explicativo para eventos ruins dessas pessoas permaneceu estável por mais de 52 anos. Assim, pôde-se afirmar que o estilo explicativo para eventos ruins pode persistir durante a vida, constituindo um fator de risco para depressão, baixos desempenhos e doença física (Burns \& Seligman, 1989).

As conseqüências do pessimismo podem ser extensas e desastrosas: humor depressivo, resignação, menos sucessos nos empreendimentos, saúde física frágil e depressão (Seligman, 1995). Pesquisas têm relacionado o pessimismo com o aumento do risco de contrair doenças infecciosas e saúde frágil (Kamen \& Seligman, 1987); com mortalidade e morbidade, mediado por variáveis como retração social, depressão, dificuldade em resolução de problemas e resposta fisiológica ao estresse (Peterson \& Seligman, 1987).

A depressão é o que mais tem sido relacionado ao pessimismo. Pesquisas empíricas com diferentes idades e em diferentes culturas têm sempre encontrado a depressão associada ao pessimismo em crianças americanas (Kaslow, Rehm \& Siegel, 1984; Robins \& Hinkley, 1989), em crianças chinesas (Yu \& Seligman, 2002), em estudantes universitários (Suraskv \& Fish, 1985) e em adultos (Peterson, Bettes \& Seligman, 1985). Outros tipos de metodologia de estudos também comprovam esta associação, como a metanálise (Gladstone \& Kaslow, 1995) e o estudo longitudinal em período de um ano e de cinco anos (Nolen-Hoeksema, Girgus \& Seligman, 1986; Nolen-Hoeksema, Girgus \& Seligman, 1992).

O estilo explicativo é aprendido durante a infância por meio das influências dos educadores. Com base na forma como os pais explicam os erros e acertos da criança ou deles próprios, desenvolve-se o estilo explicativo dos filhos (Seligman, 1995). Quando uma criança faz algo errado e um adulto briga dizendo-lhe "Você não é capaz de fazer nada correto", "Você é uma pessoa desastrada", "Você sempre se comporta mal", ensina-lhe a pensar dessa forma. Isso não significa que não se deve criticar as crianças e sim, que é preciso cuidar da maneira como fazê-lo, sem culpar a personalidade da criança, sem usar "sempre" ou "nunca". Deve-se mostrar que os erros são temporários, específicos e mutáveis. A criança precisa errar, precisa vivenciar frustrações, mas ela precisa saber como explicar seus erros e falhas, e os pais têm grande participação nesse aprendizado.

Além disso, as crianças absorvem a maneira como os pais falam sobre si e seus problemas (Seligman, 1995). Uma criança pode ouvir seu pai comentando sobre dificuldade financeira: "Eu sou mesmo um fracassado, sempre fui assim, nunca conseguirei pagar minhas dívidas, nada dá certo para mim" e assim por diante. Outra pode ouvir seu pai comentando sobre seu emprego: "Fui promovido, eu sempre trabalhei muito para isso, sempre consegui o que quis com meu esforço". Tomando por base esses discursos, seja o do pai pessimista ou do pai otimista, a criança absorve um modelo de explicação para os fatos, tendendo a imitá-lo. Assim, a postura de pensamento explicativo diante de eventos bons e ruins é primeiramente ensinada em casa. Os indivíduos aprendem a ser otimistas primeiramente pela influência dos comportamentos dos pais, como demonstra uma pesquisa recente que encontrou correlação positiva entre o pessimismo da mãe e o pessimismo do filho e correlação negativa entre sintomas depressivos da mãe e otimismo da criança (Hasan \& Power, 2002).

O estudo do relacionamento entre pais e filhos pode ser realizado por meio de estilos parentais, o que é interessante por evitar o risco de interpretações erradas a respeito de associações entre aspectos isolados da conduta dos pais e características dos filhos. Darling e Steinberg (1993) ressaltaram a importância de se manter clara a diferença entre "estilo" e "prática" parentais. O 
estilo refere-se a um padrão de comportamento parental expresso dentro de um clima emocional criado pelo conjunto das atitudes dos pais, o qual inclui as práticas parentais e também engloba outros aspectos da interação pais-filhos, tais como tom de voz, linguagem corporal, descuido, mudança de humor (Darling \& Steinberg, 1993). Os estilos são "manifestações dos pais em direção a seus filhos que caracterizam a natureza da interação entre esses" (Reppold, Pacheco, Bardagi \& Hutz, 2002, p. 23). Já as práticas parentais correspondem a comportamentos com conteúdos específicos e com objetivos de socialização. As práticas são apenas estratégias com o objetivo de suprimir comportamentos considerados inadequados ou de incentivar a ocorrência de comportamentos adequados (Alvarenga, 2001).

Essa definição de estilo parental passou por um processo de transformação desde o início dessa linha de pesquisa, que remonta à década de 60. Baumrind, a iniciadora dessa linha de estudos, começou a tratar os comportamentos dos pais sob três protótipos de controle: o controle autoritário, o controle permissivo e o controle autoritativo, um modelo teórico que foi desenvolvido com base em pesquisas sobre comportamentos dos pais associados a comportamentos competentes de crianças de pré-escola (Baumrind, 1967, 1971; Baumrind \& Black, 1967). O termo "autoritativo" é de difícil tradução, sem correspondente em português, portanto pesquisadores brasileiros mantiveram o seu nome (Costa, Teixeira e Gomes, 2000); outros pesquisadores adotaram nomes alternativos para esse estilo como democrático-recíproco (Oliveira e cols., 2002) ou competente (Bee, 1996).

Cada um desses protótipos parentais são caracterizados por Baumrind (1966). Pais autoritativos tentam direcionar as atividades de suas crianças de maneira racional e orientada, incentivam o diálogo e exercem firme controle nos pontos de divergência, colocando sua perspectiva de adulto e reconhecendo que a criança possui interesses próprios e maneiras particulares. Pais autoritários modelam, controlam e avaliam o comportamento da criança de acordo com regras de conduta estabelecidas e normalmente absolutas; são a favor de medidas punitivas para lidar com aspectos da criança que entram em conflito com o que eles pensam ser certo. Os pais permissivos tentam se comportar de maneira não-punitiva e receptiva diante dos desejos e ações da criança; apresentam-se para seus filhos como um recurso para realização de seus desejos e não como um modelo, nem como um agente responsável por moldar ou direcionar seu comportamento.

A tipologia de controle parental de Baumrind foi reformulada por Maccoby e Martin (1983), que subdividiram o estilo permissivo em indulgente $\mathrm{e}$ negligente. Assim, os três estilos iniciais se transformaram em quatro e estes passaram a ser definidos por meio das dimensões de exigência (demandingness) e responsividade (responsiveness). A exigência refere-se ao quanto os pais controlam o comportamento dos filhos, colocando regras e exigindo o cumprimento delas. A responsividade refere-se ao quanto os pais são amorosos, responsivos e envolvidos, aceitando a responsabilidade de responderem, o quanto possível, aos pontos de vista e razoáveis exigências dos filhos (Maccoby \& Martin, 1983). Os pais autoritários são exigentes, mas não são responsivos; pais indulgentes são responsivos, mas não são exigentes; pais autoritativos são tanto exigentes quanto responsivos; pais negligentes não são exigentes nem responsivos.

Um estilo parental negligente não pode ser confundido com a negligência abusiva, a qual é considerada uma violência contra a criança e refere-se a prejuízo ou risco como resultado de formas inadequadas de nutrição, vestimenta, higiene e supervisão (Roig \& Ochotorena, 1993). Já o estilo parental negligente refere-se aos pais que não se envolvem com seus papéis de pais e, a longo prazo, os componentes do papel parental tendem a diminuir cada vez mais, às vezes a desaparecer, até restar uma mínima relação funcional entre pais e filhos (Maccoby \& Martin, 1983).

Muitas pesquisas têm sido desenvolvidas utilizando a tipologia de estilos parentais e vários instrumentos têm sido elaborados para medir os estilos. Lamborn, Mounts, Steinberg e Dornbush (1991) desenvolveram duas escalas, uma de responsividade e a outra de exigência, e a combinação das dimensões permite classificar o estilo parental dos pais. Essas duas escalas foram traduzidas para o português e validadas no Brasil por Costa, Teixeira e Gomes (2000).

Com os instrumentos de medida dos estilos parentais, pesquisadores têm avaliado o quanto esses estilos estão associados a diferentes aspectos de desenvolvimento dos filhos. Os filhos de pais autoritativos têm sido associados sempre a aspectos positivos, como a assertividade, maturidade, responsabiliade social, conduta independente e empreendedora (Baumrind, 1967, 1971; Baumrind \& Black, 1967), alto índice de competência psicológica e baixo índice de disfunção comportamental e psicológica (Lamborn e cols., 1991; Steinberg, Lamborn, Darling, Mounts \& Dornbusch, 1994). Além disso, filhos de mães autoritativas são mais propensos a levar em conta a perspectiva dos outros e a entender as idéias dos outros (Knight, 2000). Crianças com pais autoritativos são capazes de explorar a escolha de uma profissão por si mesmas (Kerka, 2000). Enfim, filhos de pais autoritativos são vistos como social e instrumentalmente mais competentes do que os filhos de pais não autoritativos (Darling \& Steinberg, 1993).

Já os filhos de pais autoritários possuem bom rendimento nos estudos, mas são pressionados a 
corresponder a expectativas dos pais com respeito à educação e à escolha profissional (Kerka, 2000). Os filhos de mães autoritárias possuem comportamento de externalização, como a agressão verbal ou física, destruição de objetos e mentira; e de internalização, como a retração social, depressão e ansiedade (Oliveira e cols., 2002). Em outros estudos os filhos de pais autoritários foram descritos como tendo tendência para um desempenho escolar moderado, sem problemas de comportamento, mas eles possuem pouca habilidade social, baixa auto-estima e alto índice de depressão (Darling, 1999). Outro efeito encontrado do estilo parental autoritário é a transmissão deste estilo para os filhos. As filhas educadas por mães autoritárias tendem a adotar esse mesmo estilo parental com seus próprios filhos (Oliveira e cols., 2002).

Os filhos de pais permissivos tendem a possuir um pior desempenho nos estudos, a envolver-se com problemas de comportamento, como agressividade, e são menos independentes. Apresentam, no entanto, boas habilidades sociais, boa auto-estima e baixo índice de depressão (Darling, 1999).

Os resultados mais negativos estão relacionados com os filhos de pais negligentes, que possuem o menor desempenho em todos os domínios. Eles têm dificuldade em desenvolver autoconhecimento e de diferenciar seus próprios objetivos profissionais dos objetivos dos pais (Kerka, 2000), possuem baixo rendimento escolar, baixa auto-estima (Darling, 1999), podem ter um desenvolvimento atrasado, problemas afetivos e comportamentais (Quintin, 2001).

Todas essas pesquisas, que associam de alguma forma a maneira como os pais educam os filhos com características desses últimos, demonstram como o estudo dos estilos parentais pode ser útil para o melhor desenvolvimento das crianças. A presente pesquisa teve como objetivo principal dar continuidade a esses estudos, investigando se os diferentes estilos parentais podem estar influenciando e/ou contribuindo no desenvolvimento do otimismo nas crianças.

\section{Método}

\section{Participantes}

Participaram desta pesquisa 280 crianças de $4^{\mathrm{a}}$ série, de duas escolas municipais da região de Curitiba. A idade dos participantes variou entre nove e doze anos.

\section{Instrumentos}

Foram utilizados dois instrumentos. O primeiro foi o Questionário de Estilo de Atribuição Comportamental de Crianças (Children's Attributional Style Questionnaire - CASQ) de Seligman (1995), que mede o otimismo da criança. O segundo foi o instrumento composto pelas Escalas de Exigência e Responsividade, para avaliar os estilos parentais.

O primeiro consiste num questionário de 48 questões, cada uma apresentando situações hipotéticas e duas possíveis explicações sobre o porquê da ocorrência da situação. Por exemplo, para a questão "Você conta uma piada e ninguém ri", as opções de resposta são: a) Eu não conto piadas muito bem; b) A piada é tão conhecida que não tem mais graça. As 48 questões avaliam seis dimensões (cada uma contendo oito questões): permanência, difusão e personalização para eventos bons e para ruins.

O segundo instrumento contém 16 questões e é dividido em duas escalas (a de exigência com 6 questões e a de responsividade com 10). As questões das escalas foram avaliadas por meio de um sistema Likert de 3 pontos. Essas duas escalas foram validadas no Brasil para adolescentes por Costa e cols. (2000), que se basearam nas usadas por Lamborn e cols. (1991). Com a devida autorização, houve adaptações das escalas para esta pesquisa, possibilitando assim a aplicação para crianças.

\section{Procedimento}

Primeiramente foi feito contato com Costa e cols. para a autorização do uso das escalas e devidas adaptações, sendo estas realizadas; e contato com Seligman, para este autorizar a tradução e utilização do CASQ. O processo de tradução e adaptação do CASQ para a língua portuguesa foi feito pelo procedimento de back-translation, realizado por pessoas com proficiência em língua inglesa. Além desse processo de tradução, houve certas adaptações ao contexto brasileiro. Foram contatadas duas escolas e, com sua autorização, a aplicação foi realizada em grupos contendo no máximo sete crianças.

O Questionário de Estilo de Atribuição Comportamental de Crianças foi analisado por meio da contagem do escore total de otimismo, dos escores dos eventos bons e ruins e do escore de passividade. O escore total de otimismo foi obtido subtraindo o escore de eventos ruins do de eventos bons. Nolen-Hoeksema, Girgus e Seligman (1992) encontraram valores de consistência interna muito baixos para cada uma das seis dimensões do $C A S Q$. Ainda que essas dimensões sejam distintas teoricamente, esses autores agrupam-nas em eventos bons e ruins para realizar a análise de dados. O mesmo ocorreu na presente pesquisa, portanto optou-se em seguir esse mesmo procedimento.

Para as escalas de exigência e responsividade foram calculados os escores totais de cada uma; quando se considerou pais e mães combinados, os escores foram somados. Assim, para a análise das dimensões de responsividade e de exigência foi utilizada a mediana da amostra para avaliar se os escores foram altos ou 
baixos, excluindo-se aqueles que obtiveram valor igual à mediana. Foi feita então a classificação dos estilos parentais da seguinte forma: pais com escore alto em ambas dimensões correspondem ao estilo autoritativo; com escore baixo em ambas dimensões, ao estilo negligente; com escore baixo em responsividade e alto em exigência, ao estilo autoritário; com escore alto em responsividade e baixo em exigência, ao estilo indulgente. Os cálculos de relação entre as variáveis foram realizados por meio do programa estatístico Statistical Package for the Social Sciences (SPSS).

\section{Resultados e Discussão}

\section{Freqüências dos estilos parentais}

As escalas de Responsividade e Exigência, adaptadas para crianças, permitiram a classificação dos pais quanto a seus estilos dentro das quatro categorias, quais sejam, autoritativo, autoritário, permissivo e negligente. As freqüências obtidas mediante os escores somados do pai e da mãe foram 11,4\% indulgentes; $12,1 \%$ autoritários; $38,3 \%$ autoritativos; $38,3 \%$ negligentes.

A freqüência dos estilos demonstra que a maior parte dos pais e mães está se encaixando nos pontos extremos da classificação de estilos parentais, pois, ou são muito exigentes e muito responsivos (autoritativos), ou são pouco exigentes e pouco responsivos (negligentes). A alta freqüência de pais negligentes também esteve presente em outras pesquisas, como nas de Lamborn e cols. (1991) e de Costa e cols. (2000) $(37,3 \%$ e 35,5\%, respectivamente). $\mathrm{O}$ fato de o estilo autoritativo possuir alta freqüência é um bom sinal, pois todas as pesquisas realizadas nessa área mostram que pais autoritativos educam melhor seus filhos (Lamborn e cols., 1991; Steinberg e cols., 1994; Kerka, 2000; Knight, 2000; Oliveira e cols., 2002). Já o fato de o estilo negligente possuir alto índice de freqüência é muito preocupante, pois mesmo que este estilo não possa ser considerado maltrato contra a criança, representa um fator de risco para que isso ocorra.

\section{Médias e frequiências do otimismo}

O CASQ fornece escores entre $-24 \mathrm{e}+24 . \mathrm{Na}$ presente pesquisa os valores variaram entre $-6 \mathrm{e}+16$. A média encontrada para as meninas foi de 2,93 , com um desvio padrão de 4,5; e a média encontrada para os meninos foi de 2,54, com um desvio padrão de 3,4. Esses valores diferiram dos encontrados por Seligman (1995), que foram de 6,50 para as meninas e 5,05 para os meninos. Esse autor afirma que para uma criança entre 8 e 12 anos ser considerada um tanto pessimista deve apresentar um escore total de otimismo menor que 5,00 se for menina, e menor que 3,00 se for menino. Para ser considerada muito pessimista e com risco de depressão deve apresentar um escore total de otimismo menor que 4,00 se for menina, e menor que 1,50 se for menino. Esses valores foram definidos na amostra americana por meio dos percentis, e correspondem na presente pesquisa aos valores de 0,0 para meninas e 1,0 para meninos, abaixo dos quais essas crianças podem ser consideradas um tanto pessimistas; $-1,0$ para meninas e 0,0 para meninos, abaixo dos quais essas crianças podem ser consideradas muito pessimistas e com risco de depressão.

Pode-se perceber que os valores correspondentes na amostra desta pesquisa são muito mais baixos que os valores encontrados na amostra americana fornecida por Seligman (1995). Não se pode, porém, afirmar que as crianças brasileiras são mais pessimistas que as americanas. Esse tipo de comparação, entre duas culturas, deve ser feito com muia cautela, pois envolve diversas variáveis, como a forma de compreender e interpretar o mundo. A diferença cultural das amostras se apresenta como uma limitação na interpretação dos dados da pesquisa aqui descrita.

Outras pesquisas foram realizadas em amostras culturais diversas, e diferentes resultados foram encontrados. O estilo explicativo esteve relacionado com sintomas depressivos na amostra de crianças chinesas ( $\mathrm{Yu}$ \& Seligman, 2002), mas esta relação não ocorreu nas amostras de crianças afro-americanas e nas crianças latinas (porto-riquenhas) (Cardemil, Reivich \& Seligman, 2002).

\section{Relação entre otimismo e estilos parentais}

As relações encontradas entre o grau de otimismo e comportamentos dos pais foram investigados de duas formas. A primeira foi por meio da classificação dos estilos parentais, e a segunda por meio das duas dimensões de responsividade e exigência.

Aplicando o teste estatístico Anova, pôde-se investigar se os estilos parentais relacionam-se com o grau de otimismo. Comprovou-se a existência de relação significativa entre o grau de otimismo e os estilos parentais $(F=6,736 ; p=0,000)$. A Tabela 1 apresenta $o$ resultado da prova de Tukey, que mostra como se distribuíram as médias dos escores de otimismo entre os estilos parentais. 
Tabela 1 - Médias do Grau de Otimismo para cada Estilo, Valores de F e P e Discriminação dos Grupos pela Prova de Tukey

\begin{tabular}{lccc}
\hline & Ambos & Pais & Mães \\
\hline Negligentes & $1,66^{\mathrm{a}}$ & $1,77^{\mathrm{a}}$ & $1,43^{\mathrm{a}}$ \\
Autoritários & 2,44 & 2,72 & 1,75 \\
Indulgentes & 2,86 & 3,32 & 2,74 \\
Autoritativos & $4,35^{\mathrm{a}}$ & $4,50^{\mathrm{a}}$ & $4,59^{\mathrm{a}}$ \\
\hline $\mathrm{F}$ & 6,736 & 6,068 & 8,681 \\
$\mathrm{p}$ & 0,000 & 0,001 & 0,000 \\
\hline
\end{tabular}

$\mathrm{a}=$ grupos que possuem diferença significativa

A prova de Tukey mostrou haver uma diferença significativa na distribuição dos escores de otimismo entre os estilos autoritativo e negligente, o que não ocorreu para os estilos autoritário e indulgente. O estilo parental autoritativo apresentou as maiores médias de otimismo $(4,35 ; 4,50 ; 4,59)$; o estilo negligente, as menores $(1,66 ; 1,77 ; 1,43)$.

Esse resultado possui o mesmo padrão de outras pesquisas realizadas sobre estilos parentais. Na pesquisa de Lamborn e cols. (1991), adolescentes que perceberam seus pais como autoritativos estão associados a aspectos positivos, enquanto os que perceberam seus pais como negligentes estão associados a aspectos negativos; adolescentes que vêem seus pais como autoritários ou como indulgentes estão associados a traços tanto positivos quanto negativos, ou seja, estão numa faixa intermediária.

Os escores totais de otimismo obtidos pelo CASQ foram correlacionados com os escores totais da escala de Responsividade e de Exigência, possibilitando investigar se o otimismo da criança possui relação com a responsividade ou exigência de seus pais separadamente. Os resultados estão presentes na Tabela 2.

Tabela 2 - Coeficientes de Correlação de Pearson entre Escore de Otimismo, Dimensões de Responsividade e Exigência dos Pais

\begin{tabular}{clc}
\hline & & Otimismo \\
\hline \multirow{2}{*}{ pai } & Exigência & $0,246^{*}$ \\
& Responsividade & $0,209^{*}$ \\
\hline \multirow{2}{*}{ mãe } & Exigência & $0,236^{*}$ \\
& Responsividade & $0,208^{*}$ \\
\hline \multirow{2}{*}{ ambos } & Exigência & $0,279^{*}$ \\
& Responsividade & $0,236^{*}$ \\
\hline
\end{tabular}

${ }^{*} \mathrm{p}=0,000$

O escore de otimismo está positivamente correlacionado com as duas dimensões, responsividade e exigência, tanto dos pais e mães separados como combinados. Isso significa que as crianças que percebem seus pais como mais exigentes e mais responsivos são aquelas que são mais otimistas. Nota-se, porém, que as correlações, apesar de significativas, não tiveram valores altos por provável intervenção de outras variáveis como nível socioeconômico, desempenho acadêmico, relacionamento com pares, entre outros.

Essa relação apenas confirma a relação encontrada entre crianças mais otimistas e pais autoritativos. Essa relação pode ser explicada pelo fato de que os pais autoritativos estão numa posição de controle das regras e ao mesmo tempo numa posição de compreensão e envolvimento, possibilitando um relacionamento bidirecional. Essas duas posições caminham juntas nos pais autoritativos, os quais representam o estilo ideal de educação justamente por conseguir equilibrar controle e envolvimento. Quando os pais fazem exigências e compreendem o lado dos filhos, ensinam da melhor forma quais são as regras e limites para se obter sucesso, explicando os porquês. Esse clima gerado pela combinação da responsividade com a exigência dos pais só pode ser favorável ao otimismo na criança, pois ela aprende que tem capacidade para sozinha lidar com sucessos e frustrações, que pode fazer novas tentativas e obter melhores resultados.

\section{Relação entre eventos bons/ruins e estilos parentais.}

Os eventos bons e os ruins provaram ser diferentes e opostos por se correlacionarem de forma significativa e negativa $(r=-0,218 ; \mathrm{p}<0,001)$. Com base nesse resultado procurou-se investigar se essas duas dimensões do otimismo estão relacionadas com os comportamentos dos pais. 
A correlação entre o escore de eventos ruins e cada uma das dimensões de estilo parental (responsividade e exigência) foi significativa e negativa $(\mathrm{r}=-0,218$ e $\mathrm{p}<0,001$ para exigência; $\mathrm{r}=-0,121$ e $\mathrm{p}<$ 0,050 para responsividade). O escore de eventos ruins não apresentou relação estatística significativa com as categorias de estilos parentais $(\mathrm{F}=3,596 ; \mathrm{p}>0,05)$. Apesar de não haver diferença significativa, as menores médias estiveram relacionadas com o estilo autoritativo e as maiores médias ao estilo negligente. A correlação entre o escore de eventos bons e cada uma das dimensões de estilo parental foi significativa e positiva $(\mathrm{r}=0,198$ e $\mathrm{p}<0,050$ para exigência; $\mathrm{r}=0,232$ e $\mathrm{p}<$ 0,001 para responsividade). O escore de eventos bons se apresentou estatisticamente relacionado com os estilos parentais $(F=4,296$; $p<0,050)$, demonstrando que as maiores médias de eventos bons estão relacionadas no estilo parental autoritativo e que as menores médias estão ao estilo negligente.

Quanto maior o escore de eventos ruins, mais pessimista é a criança e quanto maior o escore de eventos bons, mais otimista é a criança (Seligman, 1995). Assim, mais uma vez se confirma que pais menos responsivos e menos exigentes possuem filhos mais pessimistas e vice-versa.

\section{Relação entre escore de passividade e estilos parentais.}

O escore de passividade indica como a criança reage diante de eventos ruins. Ou seja, quanto maior o escore, mais ela reage de forma passiva, desistindo de tentar novamente. A correlação entre o escore de passividade $\mathrm{e}$ as dimensões de estilo parental foi significativa e negativa $(\mathrm{r}=-0,274$ e $\mathrm{p}<0,001$ para exigência; $r=-0,143$ e $p<0,050$ para responsividade). Assim, quanto mais responsivos e mais exigentes são os pais, menos passivos são os filhos e, por isso, as menores médias de passividade estão relacionadas de forma significativa aos pais autoritativos e as maiores aos pais negligentes $(F=6,858 ; p<0,001)$.

Esse resultado parece indicar de que maneira a negligência dos pais prejudica o desenvolvimento dos filhos, pois estes tendem a ser mais passivos diante das derrotas, desistem mais rapidamente de novas oportunidades. Já os filhos de pais autoritativos tendem a ser menos passivos, eles se recuperam de derrotas mais facilmente, acreditam em novas possibilidades de conseguir o que querem e, talvez por isso, apresentem maior autonomia. A posição simultânea de estabelecimento claro de regras e de compreensão e participação dos pais autoritativos faz com que os filhos cresçam com maior autonomia, permitindo que consigam certas conquistas com seus próprios esforços num movimento de auto-afirmação. Esta questão da autonomia pode estar ligada à maior facilidade de fazer escolhas, como a profissional. Filhos de pais autoritativos escolhem sua profissão por si mesmos enquanto os filhos de pais negligentes têm maior dificuldade em reconhecer seus próprios objetivos profissionais (Kerka, 2000).

\section{Conclusões}

Os dados obtidos por meio do Questionário de Estilo de Atribuição Comportamental de Crianças (tradução e adaptação do Children's Attributional Style Questionnaire) apresentaram relação coerente com os dados das Escalas de Exigência e Responsividade. O objetivo de verificar se os estilos parentais estão relacionados com o otimismo das crianças foi para salientar a importância da educação fornecida pelos pais, pois cabe a eles, em primeira mão, ações efetivas para as crianças se desenvolverem da forma mais saudável possível. É necessário esclarecer que em nenhum momento houve a pretensão de estabelecer uma relação causal, única e suficiente, entre estilos parentais e otimismo na criança. Certamente outras variáveis contribuem para o desenvolvimento do estilo explicativo da criança, afinal os comportamentos dos indivíduos são multideterminados. A presente pesquisa apenas optou por enfocar a interação pais-filhos e mostrar que essa educação gera conseqüências no comportamento da criança.

Encontrou-se que são os pais autoritativos que mais contribuem para os filhos desenvolverem um "estilo explicativo" otimista, e o fato de os pais autoritativos terem tido uma representação considerável na amostra pode ser um bom indício. No entanto, a porcentagem de pais autoritativos foi equivalente à de pais negligentes, e tal resultado é preocupante. Os filhos de pais negligentes foram os que apresentaram menores escores de otimismo. O baixo otimismo traz sérias conseqüências, como humor depressivo, resignação, baixo rendimento, e mesmo saúde física vulnerável, havendo também um risco muito maior de desenvolvimento de depressão futuramente (Seligman, 1995).

A negligência por parte dos pais é grave, mas deve-se levar em conta que muitas vezes eles não possuem consciência desse comportamento. Portanto, pretende-se chamar a atenção para o fato de os psicólogos poderem auxiliar os pais para que estes eduquem seus filhos de forma consciente e não de forma apenas intuitiva. Os conhecimentos gerados nas pesquisas (como a relação entre estilo parental e otimismo na criança) contribuem muito para esse movimento. A investigação das relações entre os comportamentos dos pais e dos filhos fornece subsídios para alertar os pais quanto às conseqüências de seus atos e permite aconselhá-los sobre como podem mudar seus próprios comportamentos em benefício de seus filhos. 
Este trabalho com pais, no intuito de modificar seus comportamentos para com os filhos, pode se enquadrar dentro do contexto da Psicologia Positiva, pois é uma forma de promover um bom desenvolvimento das crianças. Essas crianças terão a possibilidade de levar uma vida mais saudável em diversos aspectos (psicológicos, cognitivos, sociais) e ter mais sucesso em seus empreendimentos.

Assim, parece que uma educação equilibrada em casa (pais autoritativos) pode formar pessoas melhores, que sabem lidar melhor com problemas (de forma otimista), o que pode se refletir em uma melhora de dimensão social. O investimento na prevenção de problemas por meio da interação pais-filhos foi, assim, a motivação da presente pesquisa, que buscou verificar como os pais podem contribuir para um desenvolvimento saudável de suas crianças.

\section{Referências}

Alvarenga, P. (2001). Práticas educativas parentais como forma de prevenção de problemas de comportamento. Em H. J. Guilhardi (Org.). Sobre comportamento e cognição, (Vol. 8, pp. 54-60). Porto Alegre: ESETec Editores Associados.

Baumrind, D. (1966). Effects of authoritative control on child behavior. Child Development, 37, 887-907.

Baumrind, D. (1967). Child care practices anteceding three patterns of preschool behavior. Genetic Psychology Monographs, 75 (1), 43-88.

Baumrind, D. (1971). Current patterns of parental authority. Developmental Psychology, 4, 1-103.

Baumrind, D. \& Black, A. (1967). Socialization practices associated with dimensions of competence in preschool boys and girls. Child Development, 38, 291-327.

Bee, H. (1996). A crianca em desenvolvimento. Porto Alegre: Artmed.

Burns, M. O. \& Seligman, M. E. P. (1989). Explanatory style across the life span, evidence for stability over 52 years. Journal of Personality and Social Psychology, 56 (3), 417-477.

Cardemil, E. V., Reivich, K. J. \& Seligman, M. E. (2002). The prevention of depressive symptoms in low-income minority middle-school students. Prevention and Treatment, 5, 32-37.

Costa, F. T., Teixeira, M. A. P. \& Gomes, W. B. (2000). Responsividade e exigência: duas escalas para avaliar estilos parentais. Psicologia: Reflexão e Crítica, 13 (3), 46-52.

Darling, N. \& Steinberg, L. (1993). Parenting style as context: an integrative model. Psychological Bulletin, $113,487-496$.
Gladstone, T. R. G. \& Kaslow, N. J. (1995). Depression and attributions in children and adolescents: a metaanalytic review. Journal of Abnormal Child Psychology, 23 (5), 597-606.

Hasan, N. \& Power, T. G. (2002). Optimism and pessimism in children: a study of parenting correlates. International Journal of Behavioral Development, 26 (2), 185-191.

Kamen, L. P. \& Seligman, M. E. (1987). Explanatory style and health. Current Psychology: Research and Reviews, 6 (3), 207-218.

Kaslow, N. J., Rehm, L. P. \& Siegel, A. W. (1984). Social-cognitive and cognitive correlates of depression in children. Journal of Abnormal Child Psychology, 12 (4), 605-620.

Kerka, S. (2000). Parenting and career development. ERIC digest. № 214. ERIC Clearinghouse on adult, career, and vocational education, Columbus, $\mathrm{OH}$. Office of Educational Research and Improvement (ED), Washington, DC. (ED 99 CO 0013) $<$ http://ericacve.org/docs/dig214.pdf >

Knight K. H. (2000). Relationship of connected and separate knowing to parental style and birth order. Sex Roles: A Journal of Research, August.

Lamborn, S. D., Mounts, N. S., Steinberg, L. \& Dornbusch, S. M. (1991). Patterns of competence and adjustment among adolescents from authoritative, authoritarian, indulgent, and neglectful families. Child Development, 62, 1049-1065.

Maccoby, E. \& Martin, J. (1983). Socialization in the context of the family: parent-child interaction. Em E. M. Hetherington \& P. H. Mussen (Org.). Handbook of child psychology. Socialization, personality, and social development. 4. ed. (vol. 4, pp. 1-101). New York: Wiley.

Nole-Hoeksema, S., Girgus, J. S. \& Seligman, M. E. (1986). Learned helplessness in children: a longitudinal study of depression, achievement, and explanatory style. Journal of Personality and Social Psychology, 51 (2), 435-442.

Nolen-Hoeksema, S., Girgus, J. S. \& Seligman, M. E. P. (1992). Predictors and consequences of childhood depressive symptoms a 5-year longitudinal study. Journal of Abnormal Psychology, 101 (3), 405-422.

Oliveira, E. A., Marin, A. H., Pires, F. B., Frizzo, G. B., Ravanello, T. \& Rossato, C. (2002). Estilos parentais autoritário e democrático-recíproco intergeracionais, conflito conjugal e comportamentos de externalização e internalização. Psicologia Reflexão e Crítica, 15 (1), 1-11.

Peterson, C. \& Seligman, M. E. (1987). Explanatory style and illness. Journal of Personality, 55 (2), 237-265.

Psico-USF, v. 8, n. 1, p. 71-79, Jan./Jun. 2003 
Peterson, C., Bettes, B. A. \& Seligman, M. E. (1985). Depressive symptoms and unprompted causal attributions: content analysis. Behaviour Research and Therapy, 23 (4), 379-382.

Reppold, C. T., Pacheco, J., Bardagi, M. \& Hutz, C. S. (2002). Prevenção de problemas de comportamento e desenvolvimento de competências psicossociais em crianças e adolescentes: uma análise das práticas educativas e dos estilos parentais. Em C. S. Hutz (Org.). Situaçôes de risco e vulnerabilidade na infância e adolescência: aspectos teóricos e estratégias de intervenção. (pp. 9-51). São Paulo: Casa do Psicólogo.

Robins, C. J. \& Hinkley, K. (1989). Social-cognitive processing and depressive symptoms in children: a comparison of measures. Journal of Abnormal Child Psychology, 17 (1), 29-36.

Roig, A. M. \& Ochotorena, J. P. (1993). Maltrato y abandono en la infancia. Barcelona: Ediciones Martínez Roca.

Seligman, M. E. P. (1995). The optimistic cbild: a proven program to safeguard children against depression and build lifelong resilience. New York: Harper Perennial.

Seligman, M. E. P. \& Csikszentmihalyi, M. (2000). Positive Psychology: an introduction. American Pscybologist, 55, 5-14.

Steinberg, L., Lamborn, S. D., Darling, N., Mounts, N. S. \& Dornbusch, S. M. (1994). Over-time changes in adjustment and competence among adolescents from authoritative, authoritarian, indulgent, and neglectful families. Child Development, 65, 754-770.

Suraskv, J. \& Fish, J. M. (1985). Cognitive distortion in depression: a comparative experimental analog test of the beck and reformulated Seligman models. Estudos de Psicologia, 2 (2-3), 51-80.

Yu, D. L. \& Seligman, M. E. P. (2002). Preventing depressive symptoms in Chinese children. Prevention and Treatment, 5, 38-44.

Sobre os autores:

Lidia Natália Dobrianskyj Weber é doutora em Psicologia Experimental pela USP, professora do Mestrado em Psicologia da Infância e da Adolescência da UFPR, coordenadora do Laboratório do Comportamento Humano.

Olivia Justen Brandenburg é aluna do quarto ano do curso de Psicologia da UFPR, bolsista de iniciação científica (PIBIC/CNPq).

Ana Paula Viezzer é aluna do quarto ano do curso de Psicologia da UFPR, bolsista de iniciação científica (PIBIC/CNPq). 
